\title{
Metode explicit instruction terhadap keterampilan mengolah kue nusantara bagi mahasiswa berkebutuhan khusus (tunarungu)
}

\author{
Rina Asmaul ${ }^{1 *}$, Yunus Karyanto ${ }^{1}$, Ana Rafikayati² \\ ${ }^{1}$ Prodi Pendidikan Vokasi Kesejahteraan Keluarga, Universitas PGRI Adi Buana, 60234, Indonesia. \\ ${ }^{2}$ Prodi Pendidikan Khusus, Universitas PGRI Adi Buana, 60234, Indonesia. \\ E-mail: asmaulrina900@ gmail.com, Telp: 081214866787
}

\begin{abstract}
Abstrak: Kue nusantara penting di lestarikan keberadaannya karena merupakan salah satu warisan budaya Indonesia dengan cara mengenalkan macam-macam jenis dan proses pengolahannya. Oleh karena itu proses pembelajaran keterampilan mengolah kue nusantara memerlukan metode yang tepat khususnya pada mahasiswa berkebutuhan khusus (tunarungu). Tujuan penelitian ini yaitu mendiskripsikan peranan metode explicit instruction terhadap keterampilan mengolah kue nusantara bagi mahasiswa tunarungu. Jenis penelitian yang di gunakan yaitu studi kepustakaan (library research). Teknik pengumpulan data yaitu dengan metode dokumentasi. Sumber data yang digunakan penelitian ini yaitu dari jurnal, buku dan artikel terkait tentang metode explicit instruction terhadap keterampilan mengolah kue nusantara bagi mahasiswa tunarungu. Teknik analisis data dalam penelitian ini yaitu analisis isi dengan pengkajian dilakukan pengecekan ulang antar pustaka. Hasil penelitian ini adalah metode explicit instruction berperan penting dalam keterampilan mengolah kue nusantara yakni dengan menerapkan sesuai langkah-langkah pada metode explicit instruction yang diajarkan selangkah demi selangkah oleh dosen agar mahasiswa tunarungu memahami dalam setiap langkah pada keterampilan mengolah kue nusantara yang diajarkan.
\end{abstract}

Kata Kunci: metode explicit instruction, mahasiswa tunarungu

\section{Explicit instruction method against the skills of processing traditional cake for students with special needs (hearing impairment)}

\begin{abstract}
Archipelago cake is important to preserve its existence because it is one of Indonesia's cultural heritage by introducing various types and processing processes. Therefore, the learning process of Indonesian cake processing skills requires the right method, especially for students with special needs (hearing impairment). The purpose of this study is to describe the role of the explicit instruction method on the skills of processing Indonesian cakes for students with hearing impairment. The type of research used is library research. The technique of collecting data is the documentation method. Sources of data used in this study are journals, books and related articles about the explicit instruction method on the skills of processing Indonesian cakes for students with special needs (deaf). The data analysis technique used in this research is content analysis, by means of cross-checking between libraries. The results of this study are the explicit instruction method plays an important role in the skills of processing Indonesian cakes, namely by applying the appropriate steps to the explicit instruction method which is taught step by step by the lecturer so that deaf students understand in each step the skills to process the archipelago cake being taught.
\end{abstract}

Keywords: explicit instruction method, hearing impairment students

\section{PENDAHULUAN}

Pendidikan bagi anak berkebutuhan khusus (ABK) baik di sekolah reguler dan sekolah luar biasa hakekatnya adalah untuk membantu anak mengembangkan potensinya, Tujuan pembelajaran keterampilan yang di berikan untuk membekali ABK agar memiliki keterampilan kerja yang bermanfaat pasca sekolah (Ishartiwi, 2010). Wardani (2013: 5) berpendapat bahwa anak berkebutuhan khusus berhak mendapatkan pendidikan, tidak hanya diberikan pada anak yang berkondisi emosi, sosial dan fisik yang normal saja. Jenis-jenis anak berkebutuhan khusus diantaranya yaitu tunanetra, tunarungu, tunagrahita, tundaksa, dan autis, pernyataan tersebut sesuai dengan lampiran I pasal 2 ayat 3 Undang-Undang No. 10 Tahun 2017. Semua jenis anak berkebutuhan khusus memiliki kesempatan yang sama untuk memperoleh pendidikan bahkan hingga ke perguruan tinggi, termasuk diantaranya mahasiswa tunarungu. 
Mahasiswa tunarungu banyak menonjolkan kelebihannya dalam keterampilan terutama keterampilan yang minim menggunakan auditory. Kelemahannya, mahasiswa tunarungu sering kali kesulitan dalam berkomunikasi dengan lingkungan, seperti komunikasi dengan teman atau dosen ketika mereka berada di kampus. Kelemahan ini bukan berarti mahasiswa tunarungu tidak dapat meningkatkan kemampuan yang dimiliki sesuai dengan teman sebayanya. Pendapat Sumekar (2009), yaitu anak yang mengalami gangguan pendengaran dapat diartikan sebagai anak yang mengalami kehilangan seluruh atau sebagian daya pendengarannya yang diakibatkan tidak berfungsinya alat pendengaran, karena hal tersebut anak tunarungu tidak dapat memanfaatkan alat pendengarannya dalam kehidupan sehari-hari yang mereka jalani. Sesuai paparan di atas, mahasiswa tunarungu sangat penting dan perlu apabila diberikan pembelajaran yang bersifat mengasah keterampilan atau pendidikan vokasional. Menurut Farooq (2011), keterampilan vokasional merupakan kegiatan yang dirancang serta diberikan kepada peserta didik agar nantinya menjadi bekal saat pasca lulus. Sependapat dengan Muspita, Safaruddin, dkk (2018) bahwa salah satu dari penyandang disabilitas atau anak yang berkebutuhan khusus yang memungkinkan dapat membuka usaha secara profesional di bidang vokasional khususnya tata boga adalah anak dengan hambatan pendengaran (tunarungu). Metode pembelajaran yang tepat sangat perlu guna mendukung terlaksananya proses pembelajaran keterampilan yang sesuai dengan mahasiswa berkebutuhan khusus (tunarungu). Salah satu metode yang tepat yaitu metode explicit instruction.

Menurut Istarani (2011: 99) explicit instruction adalah pembelajaran yang dirancang khusus guna mengembangkan dan meningkatkan cara belajar peserta didik mengenai pengetahuan prosedural dan pengetahuan deklaratif yang dapat diajarkan dengan pola selangkah demi selangkah (bertahap), dan penekanan model pembelajaran ini adalah materi sifatnya berurutan secara sistematis yang tidak dapat dipisahkan satu sama lain. Menurut pendapat Kardi (dalam Huda 2013: 186), explicit instruction dapat berbentuk demontrasi, ceramah, praktik atau pelatihan, dan kerja kelompok. Diharapkan metode explicit instruction dapat di gunakan bagi mahasiswa tunarungu untuk dapat mengikuti pembelajaran yang ada kaitannya dengan pengembangan keterampilan atau pendidikan vokasional.

Menurut Saleh (2017: 21) pembelajaran keterampilan atau pendidikan vokasional adalah keterampilan yang diberikan kepada mahasiswa sebagai bekal dalam hidup bermasyarakat sehingga dapat bersosialisasi dengan lingkungannya. Sejalan dengan pendapat Sukmadinata dan Sayodih (2012: 40) juga mendefinisikan keterampilan vokasional sebagai wadah pendidikan untuk mempersiapkan para lulusannya untuk masuk di dunia kerja. Keterampilan tata boga merupakan salah satu mata kuliah untuk meningkatkan keterampilan mahasiswa yang berfokus pada pengelolaan, pembuatan, dan penyajian makanan (Hartaty, Yuly: 2017). Pengolahan kue nusantara merupakan salah satu mata kuliah yang menekankan keterampilan dalam mengolah aneka kue nusantara dengan berbagai macam bahan dasar. Proses pembalajarannya menuntut mahasiswa untuk kreatif dalam mengolah bahan mentah menjadi kue yang memiliki rasa yang lezat dan bergizi, serta memiliki varian rasa yang berbeda-beda sehingga memiliki nilai jual yang tinggi.

Bedasarkan hasil wawancara 10 alumni dari 2 universitas di Surabaya, diperoleh permasalahan di lapangan yang menjadi sorotan yaitu mahasiswa yang mengalami hambatan dalam pendengarannya sebagaian besar setelah lulus dari universitas kesulitan mendapatkan pekerjaan yang sesuai dengan kebutuhan mahasiswa tersebut. Hal ini terjadi karena minimnya keterampilan yang mereka miliki. Keterampilan mengolah kue nusantara sangat mendukung kemandirian mahasiswa tunarungu untuk dapat mengembangkan kreatifitas untuk menjadi pengusaha dalam menunjang kehidupannya yang lebih baik. Oleh sebab itu, penting untuk memperhatikan model pembelajaran yang akan digunakan agar mahasiswa tunarungu mampu menguasai dengan baik keterampilan yang dipelajari. Salah satu model pembelajaran yang diasumsikan sesuai dengan karakteristik belajar mahasiswa tunarungu adalah model pembelajaran expilicit instruction karena langkah pembelajaran model pembelajaran tersebut dapat mengakomodasi hambatan pendengaran yang dimiliki mahasiswa tunarungu.

\section{METODE}

Penelitian ini menggunakan jenis penelitian kepustakaan (library research). Peneliti ingin mengkaji dan menyimpulkan hasil penelitian dari jurnal dan artikel mengenai peran metode expilicit instruction terhadap keterampilan mengolah kue nusantara mahasiswa tunarungu. Cooper dkk (dalam Farisi, 2010), berpendapat bahwa jenis penelitian ini untuk mengkaji pada pengetahuan, penemuan 
yang ada pada literatur akademik untuk merumuskan kontribusi teoritis beserta metodologisnya pada topik tertentu .

Prosedur penelitian ini yaitu peneliti memilih topik permasalahan yang akan dibuat, lalu mencari informasi pada berbagai media seperti pada buku, jurnal, artikel ilmiah dan lain sebagainya. Selanjutnya mempersiapkan dalam penyajian data, dan terakhir peneliti menyusun laporan. Sumber data dalam penelitian ini diambil dari berbagai macam bahan yaitu buku, jurnal dan situs internet yang terkait dengan metode explicit instruction terhadap keterampilan mengolah kue nusantara bagi mahasiswa tunarungu.

Teknik pengumpulan data pada penelitian ini menggunakan dokumentasi dengan mencari datadata yang terkait berupa catatan, 2 buku, 5 artikel, dan 5 jurnal. Penelitian ini menggunakan metode analisis isi (contect analysis) untuk mendapatkan informasi yang akurat dan dapat diteliti lagi oleh orang lain lagi atau penelitian ulang berdasarkan konteks yang diambil, (Kripendoff, 1991).

\section{HASIL DAN PEMBAHASAN}

Hasil studi kepustakaan yang sudah dilakukan peneliti, peran metode explicit instruction terhadap mahasiswa tunarungu mampu mempermudah dalam proses pembelajaran tentang keterampilan mengolah kue nusantara mulai dari persiapan bahan, proses pengolahan, hingga penyajian. Langkah-langkah yang digunakan dalam metode explicit instruction ini yang diawali dengan dosen menjelaskan tujuan pembelajaran dengan menyiapkan mahasiswa untuk belajar dengan memberitahukan tujuan dari pembelajaran keterampilan mengolah kue nusantara yang akan diajarkan agar bisa mempersiapkan mahasiswa untuk belajar, dosen menjelaskan materi pembelajaran sesuai materi keterampilan mengolah kue nusantara dengan memberikan pengetahuan selangkah demi selangkah yaitu menjelaskan 1 langkah terlebih dahulu agar bisa naik ke langkah berikutnya. Hal ini mempermudah mahasiswa tunarungu untuk memahami keterampilan mengolah kue nusantara yang dijelaskan dari setiap Langkah. Selanjutnya, dosen merencanakan dan memberikan latihan terstruktur kepada mahasiswa dengan cara mendemonstrasikan cara memasak dihadapan mahasiswa dalam praktik mengolah kue nusantara dengan memberikan penjelasan karena mahasiswa tunarungu memerlukan cara yang konkrit agar mudah memahami. Guna memastikan tersampaikannya materi dengan baik, dosen memberikan umpan balik dengan memberikan latihan terbimbing dengan cara memberikan bimbingan pada setiap langkahnya, dan yang terakhir dosen memberikan kesempatan untuk latihan mandiri. Berdasarkan langkah-langkah yang ada di metode explicit instruction, dosen mampu memberikan latihan terstruktur dengan melakukan pembelajaran selangkah demi selangkah pada mahasiswa tunarungu yang akan berdampak dalam penguasaan suatu keterampilan dengan penerapan metode ini dapat membantu mahasiswa tunarungu memahami keterampilan mengolah kue nusantara dengan penerapan langkah-langkah yang ada agar bisa mencapai tujuan.

Terbukti dengan jurnal hasil temuan yang ada bahwasannya metode explicit instruction mampu membantu anak tunarungu dalam meningkat keterampilan mengolah makanan. Didukung hasil temuan yang relevan oleh Selfia Sulfanita (2018), bahwasannya metode explicit instruction mampu membantu meningkatkan keterampilan membuat tempe pada anak tunarungu yaitu anak yang kehilangan seluruh atau sebagian daya pendengarannya yang diakibatkan karena tidak berfungsinya sebagian atau seluruh alat pendengaran, sehingga ia tidak dapat menggunakan alat pendengarannya dalam kehidupan seharihari, ini mengalami kesulitan dalam memahami pembelajaran, maka metode explicit instruction mampu berperan penting dalam pembelajaran keterampilan tata boga dikarenakan langkah-langkah yang digunakan yaitu prosedur dengan bertahap untuk anak tunarungu yang mengalami kesulitan dalam memahami pembelajaran terbukti dengan hasil temuan yang dicantumkan nilai pre-test $59 \%$ yaitu sebelum diterapkannya metode explicit instruction pada keterampilan tata boga membuat tempe dan pada post-test terdapat peningkatan hasil belajar yaitu melebihi $70 \%$ setelah diterapkan metode explicit instruction pada keterampilan tata boga membuat tempe pada anak tunarungu.

Sama halnya hasil penelitian yang di lakukan Dasmi,Yunisa Fatma (2019) bahwasanya metode explicit instruction mampu meningkatkan keterampilan membuat stik tahu pada siswa kelas VII-B di SLB Muhammadiyah Pauh IX Padang. Rata-rata kemampuan awal siswa yaitu IPS 35,29\% dan AMT 23,52\%. Setelah dilaksanakan metode explicit instruction siklus I mendapatkan rata-rata IPS $50 \%$ dan AMT 39,7\% dan Siklus II dengan rata-rata IPS 80,87\% dan AMT 70,58\%. Adanya peningkatan kemampuan siswa yang sebelum menggunakan metode explicit instruction IPS 35,29\% dan AMT 23,52\% dan setelah menggunakannya menunjukkan peningkatan yakni 80,87\% dan AMT 70,58\%. 
Hal tersebut di atas menunjukkan bahwa metode explicit instruction mampu meningkatkan keterampilan dalam membuat stik tahu.

Arends (2001:41), mengemukakan bahwa metode explicit instruction merupakan salah satu pendekatan mengajar dengan dirancang khusus untuk pengetahuan yang dikemas secara ringkas dan dengan dilakukan bertahap yang disusun dengan baik agar dapat dipahami dengan mudah. Metode explicit instruction dicetuskan pertama kali oleh Rosenshine dkk (dalam Silviana, 2016:3), yang memiliki pengertian pembelajaran langsung yang dirancang khusus dalam pengembangan pembelajaran siswa dalam mempelajari suatu prosedur dan dengan pengetahuan deklaratif yang pembelajarannya diajarkan dengan pola yang bertahap yaitu selangkah demi selangkah. Maka metode pembelajaran explicit instruction adalah metode pembelajaran dengan strategi pendekatan yang dijelaskan oleh dosen secara langsung dengan pola belajar selangkah demi selangkah dengan berbentuk ceramah, praktik, dan kerja kelompok.

Tujuan dari metode pembelajaran yang dikemukakan Weil (dalam Rani, 2019), tentang explicit instruction yaitu memiliki waktu maksimal dalam belajar tetapi saat belajar tercapai dalam akademik dan keterampilan sehingga keterampilan siswa meningkat serta motivasi belajarnya. Didukung dengan langkah-langkah dari metode explicit instruction yang sangat membantu dalam proses pembelajaran keterampilan mengolah kue nusantara dikarenakan dosen memegang penuh kendali dari setiap langkah-langkah yang ada. Berikut langkah-langkah metode explicit instruction: dosen menjelaskan tujuan pembelajaran, dosen menjelaskan materi pembelajaran dengan memberikan pengetahuan selangkah demi selangkah, dosen merencanakan dan memberikan latihan terstruktur kepada mahasiswa, dosen memberikan umpan balik dengan memberikan latihan terbimbing pada konsep dan keterampilan, dosen memberikan kesempatan untuk latihan mandiri.

Reber (dalam Sari, 2014:20), mengemukakan bahwa keterampilan merupakan keahlian untuk melaksanakan kegiatan yang sudah terjadwal dan tersusun rapih dan menyesuaikan dengan keadaan agar bisa mencapai tujuan. Kue nusantara menurut Astrini (2013: 4) memaparkan bahwa kue nusantara mulai berkembang pada saat datangnya wisatawan untuk menikmati keindahan Indonesia. Wisatawan yang datang berkunjung dan singgah di Indonesia selain membawa budaya mereka masing-masing, mereka juga membawa kebudayaan makanannya, sehingga membawa pengaruh yang besar pada makanan dan kue-kue di Indonesia. Pembelajaran keterampilan mengolah kue nusantara terdapat lima langkah yaitu fase persiapan menyampaikan tujuan dan mempersiapkan mahasiswa, mendemonstrasikan pengetahuan dan keterampilan prosedural, membimbing pelatihan penerapan, mengecek pemahaman, memberikan umpan balik, dan memberikan kesempatan untuk latihan lanjutan. Hal ini sangat membantu mahasiswa tunarungu dalam mempelajari keterampilan mengolah kue nusantara sebelum mahasiswa melakukan praktik mandiri.

Metode explicit instruction berperan penting dan dapat membantu apabila diterapkan pada keterampilan mengolah kue nusantara karena menyesuaikan dengan karakteristik mahasiswa tunarungu yaitu hanya mampu melakukan kegiatan yang bersifat kongkrit dan mengalami hambatan dalam memahami materi yang bersifat abstrak sehingga mengakibatkan sulit dalam menyimpulkan informasi. Pembelajaran pengolahan kue nusantara memiliki beberapa kesulitan dalam proses pembuatannya, diantaranya ketepatan pemilihan bahan harus sesuai dengan metode yang di gunakan, formula yang digunakan harus tepat agar menghasilkan tekstur kue yang di inginkan, tahapan pembuatan lebih rumit dan tahapan pembuatan perlu adanya pendampingan karena resep yg digunakan tidak semua berhasil tergantung karakteristik bahan yang di gunakan. Selain itu, kue nusantara memiliki keunikan tersendiri dibandingkan kue-kue modern diantaranya kue nusantara dibuat dengan alat dan cara tradisional, bahan yang di gunakan asli lokal, dan setiap daerah di Indonesia memiliki kue khas daerah itu sendiri dengan teknik beraneka ragam. Maka metode explicit instruction yang memiliki kelebihan dapat merangsang antusias mahasiswa dalam belajar keterampilan mengolah kue nusantara, cara yang paling berpengaruh dalam mengajarkan konsep dan keterampilan yang tidak berbelit-belit. Mahasiswa tunarungu lebih mengerti karena dijelaskan secara bertahap dan dengan keterampilan mengolah kue nusantara yang harus step by step maka metode ini sangat berperan dalam mengajarkan informasi pengetahuan yang sudah disusun. Oleh karena itu metode pembelajaran explicit instruction dapat digunakan dalam pembelajaran keterampilan mengolah kue nusantara dikarenakan menggunakan langkah-langkah yang sesuai dan mempunyai umpan balik kepada mahasiswa dalam belajar mengolah kue nusantara dengan disesuaikan pada kondisi mahasiswa tunarungu yang memiliki kelemahan dalam pendengaran. 


\section{SIMPULAN}

Berdasarkan tujuh hasil penelitian yang sudah dipaparkan di atas mengenai peranan metode pembelajaran explicit instruction terhadap pembelajaran keterampilan pada mahasiswa tunarungu, dapat disimpulkan bahwa metode explicit instruction dapat meningkatkan hasil belajar dan mempermudah proses pembelajaran keterampilan salah satunya mengolah kue nusantara bagi mahasiswa tunarungu. Metode explicit instruction yang menggunakan lima langkah yaitu fase persiapan menyampaikan tujuan dan mempersiapkan mahasiswa, mendemonstrasikan pengetahuan dan keterampilan prosedural, membimbing pelatihan penerapan, mengecek pemahaman, memberikan umpan balik, dan memberikan kesempatan untuk latihan lanjutan. Mahasiswa tunarungu dapat menerapkan metode tersebut sesuai langkah-langkah yang ada dan pembelajaran yang berulang-ulang. Oleh karena itu, penting untuk dilakukan penerapan dari metode explicit instruction dikarenakan peranan yang sangat membantu mahasiswa tunarungu dalam belajar keterampilan mengolah kue nusantara.

\section{DAFTAR PUSTAKA}

Astrini, Erinna. (2013). Rencana Pelaksanaan Pembelajaran (RPP) Kue Nusantara. Bandung: Tidak diterbitkan

Arends, R.I,. 2001. Exploring Teaching: An Introduction to Education. New York: Mc Graw-Hill Companies.

Farisi, M. I. 2010. Pengembangan Asesmen Diri Siswa (Student Self-Assessment) sebagai Model Penilaian dan Pengembangan Karakter. Artikel disampaikan pada Konferensi Ilmiah Nasional “Asesmen dan Pembangunan Karakter Bangsa” HEPI UNESA 2012.

Farooq, G. 2011. "Evaluation of Curriculum of Vocational Subjects for Hearing Impaired Children". Interdiciplinary Journal of Contemporary Research in Business. Volume 3, No. 5.

Hartaty, Yuly. 2017. Peningkatan Hasil Belajar Keterampilan Tata Boga Materi Pembuatan Brownis Pisang Melalui Model Pembelajaran Eksplicit Instruction. Diakses dari https://doi.org/10.25217/ji.v2i1.97.

Ishartiwi, D. M. P. (2010). Pembelajaran Keterampilan Untuk Pemberdayaan Kemandirian Anak Berkebutuhan Khusus. UNY.

Istarani. (2011). 58 Model Pembelajaran Inovatif. Medan: Media Persada.

Huda, Miftahul. (2013). Model-Model Pengajaran dan Pembelajaran. Yogyakarta: Pustakawan Pelajar.

Kripendoff, Klaus. (1991). Analisis Isi, Pengantar Teori, dan Metodologi. Penerjemah: Fraid Wajidi. Jakarta: Rajawali Pers.

Muspita, R., Safaruddin, S., Ardisal, A., \& Sopandi, A. A. (2018). Pembelajaran Keterampilan Membuat Ikan Bakar Bagi Anak Hambatan Pendengaran. Jurnal Pendidikan Kebutuhan Khusus, 2(2), 48-50.

Rani, Amallia P S. (2019). Pengaruh Model Explicit Instruction Pada Pembuatan Cilok Sehat Terhadap Keterampilan Vokasional Bagi Anak Tunagraita Ringan. Surabaya: Universitas Negeri Surabaya. https://jurnalmahasiswa.unesa.ac.id/index.php/jurnalpendidikankhusus/article/view/27696.

Saleh, I. (2017). Peningkatan Kompetensi Melalui Program Keterampilan Vokasional di SLBB YPALB Karanganyar. Surakarta: Institut Agama Islam Negeri Surakarta.

Sari, Mulya. 2014. Peningkatan Keterampilan Tata Boga Materi Pembuatan Brownis Kukus Melalui Model Pembelajaran Eksplisit. Diakses dari https://doi.org/10.21009/PIP.281.3.

Selfia, Sulfanita. (2018). Pengaruh Model Explicit Instruction dalam Meningkatkan Keterampilan Vokasional Membuat Tempe Bagi Anak Tunarungu. Jurnal Penelitian Pendidikan Khusus. Volume 6 Nomor I. file:///C:/Users/User/Downloads/101614-26584-1-PB(1).pdf. 
JPK (Jurnal Pendidikan Khusus), 16 (2), 2020 - 80

Rina Asmaul, Yunus Karyanto

Silviana, Gina. (2016). Penggunaan Metode Explicit Instruction Untuk Meningkatkan Keterampilan Generik Sains Siswa Pada Konsep Biosafety. Diakses dari http://repository.unpas.ac.id/id/eprint/12417.

Sukmadinata, Syaodih.N. (2012). Metode Penelitian Pendidikan. Bandung: Rosda

Sumekar, G. (2009). Anak Berkebutuhan Khusus. Padang: UNP Press.

UU No.10 Tahun 2017. Lampiran 1 pasal 2 ayat 3. Tentang jenis-jenis anak berkebutuhan khusus.

Wardani, I.G.A.K. (2013). Pengantar Pendidikan Anak Berkebutuhan Khusus. Banten: Universitas Terbuka.

\section{PROFIL SINGKAT}

Rina Asmaul, S.Pd., M.Pd dilahirkan di Banyuwangi 29 Mei 1991. Anak pertama dari dua bersaudara. Masuk di TK Kartini Pesanggaran banyuwangi pada tahun 1997. Melanjutkan di SDN 3 Siliragung masuk pada tahun 1999 dan lulus pada tahun 2004. Pada tahun 2004 lanjut di SMPN I Siliragung dan lulus tahun 2007. Tahun 2007 lanjut di SMKN 3 Jember mengambil jurusan Tata Boga dan lulus tahun 2010. Dari SMK langsung melanjutkan studi di bangku kuliah dan masuk tahun 2010, masuk di Universitas PGRI Adi Buana Surabaya mengambil Jurusan S1 FKIP Prodi PKK Konsentrasi Tata Boga dan lulus tahun 2014. Guna meningkatkan bidang ilimu yang ditekuni, penulis kemudian melanjutkan studi S2 di Universitas Negeri Malang Prodi PKJ konsentrasi Tata Boga pada tahun 2015 dan lulus pada tahun 2017. Setelah lulus S2 penulis bekerja sebagai dosen di Prodi PVKK konsentrasi Tata Boga di Universitas PGRI Adi Buana Surabaya hingga saat ini. 